\title{
Effects of simulated nitrogen deposition on soil microbial community diversity in coastal wetland of the Yellow River Delta
}

\author{
Guanru Lu ${ }^{\text {a }}$, Baohua Xie ${ }^{\mathrm{a}}$, Grace A. Cagle ${ }^{\mathrm{b}}$, Xuehong Wang ${ }^{\mathrm{c}}$, Guangxuan Han ${ }^{\mathrm{a}}$, Xiaojie Wang ${ }^{\mathrm{a}}$, \\ Aixin Hou ${ }^{\mathrm{b}}$, Bo Guan ${ }^{\mathrm{a}, *}$
}

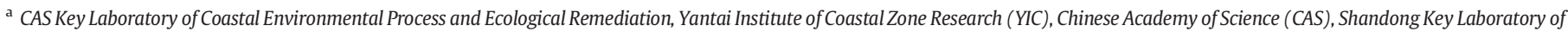
Coastal Environmental Processes, YICCAS, Yantai 264003, China

${ }^{\mathrm{b}}$ Department of Environmental Sciences, College of the Coast and Environment, Louisiana State University, Baton Rouge, LA 70803, USA

c The Institute for Advanced Study of Coastal Ecology, Ludong University, Yantai 264025, China

\section{H I G H L I G H T S}

- Nitrogen deposition affected the composition of the soil microbial community.

- The salinity was significantly correlated with the relative abundance of Gammaproteobacteria.

- Nitrogen deposition reduced the relative abundance of halophilic Halomonas.

- $\mathrm{NH}_{4}^{+}-\mathrm{N}$ significantly decreased soil microbial diversity.

\section{A R T I C L E I N F O}

\section{Article history:}

Received 19 August 2020

Received in revised form 19 October 2020

Accepted 1 November 2020

Available online 20 November 2020

Guest Editor: Junhong Bai

\section{Keywords:}

Nitrogen deposition

Soil microbial diversity

Salt content

Bacillus

The Yellow River Delta

\section{G R A P H I C A L A B S T R A C T}

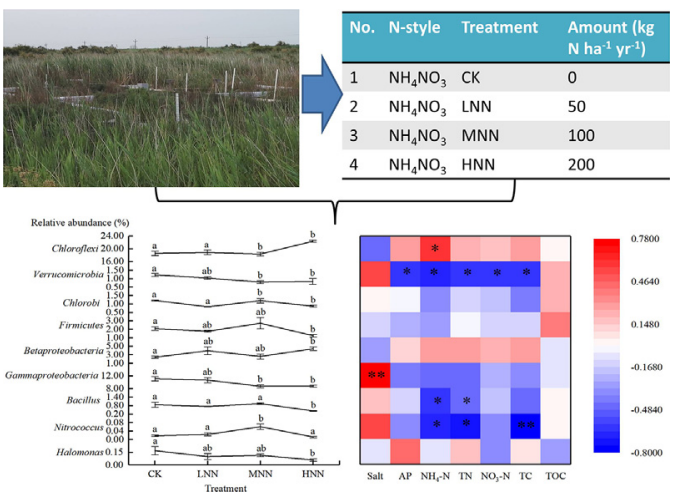

\begin{abstract}
A B S T R A C T
Due to the enhancement of human activities on the global scale, the total amount of atmospheric nitrogen $(\mathrm{N})$ deposition and the rate keep increasing, which seriously affect the structure and function of terrestrial ecosystems. In order to study the effects of $\mathrm{N}$ deposition on the soil structure and function of coastal saline wetlands, we established a long-term nitrogen deposition simulation platform in 2012 in the Yellow River delta (YRD). Herein, we analyzed the composition and diversity of the soil microbial community under different $\mathrm{N}$ deposition treatments (LNN, MNN and HNN, which stand for $50 \mathrm{~kg} \mathrm{Nha}^{-1} \mathrm{yr}^{-1}, 100 \mathrm{~kg} \mathrm{Nha}^{-1} \mathrm{yr}^{-1}$, and $200 \mathrm{~kg} \mathrm{Nha}^{-1} \mathrm{yr}^{-1}$ ) and in a water-only control $(\mathrm{CK})$. The results showed that with the increasing level of $\mathrm{N}$ deposition, $\alpha$-diversity (Shannon and Simpson indices) decreased significantly, and the composition of the microbial community changed. At the phylum level, compared with $\mathrm{CK}$, the relative abundance of Chloroflexi increased significantly under the treatment of $\operatorname{HNN}(P=0.002)$, but the relative abundance of Chlorobi $(P=0.013)$ and Verrucomicrobia $(P=0.035)$ decreased significantly. At the genus level, compared with $\mathrm{CK}$, the relative abundance of Bacillus $(P=0.01)$ and Halomonas $(P=0.042)$ increased significantly with HNN treatment. Bacillus and Nitrococcus showed a significant correlation with soil $\mathrm{NH}_{4}^{+}-\mathrm{N}$. The results suggest that the response of microorganisms to $\mathrm{N}$ deposition treatments varied by the concentration, and the deposition of a high concentration would increase the nutrients in the soil, but reduce the diversity of soil microorganisms, causing a negative impact on the coastal wetland ecosystem of the YRD.
\end{abstract}

(c) 2020 Elsevier B.V. All rights reserved.

\footnotetext{
* Corresponding author.

E-mail address: bguan@yic.ac.cn (B. Guan).
} 


\section{Introduction}

Nitrogen is a key factor affecting the structure, dynamics, ecological diversity and function of many ecosystems. It is also one of the most important nutrients in the ecosystem (Huang et al., 2020a, 2020b). The mobility of available nitrogen species means that their impact spreads regionally and globally (Vitousek et al., 1997). The average soil nitrogen in natural ecosystems in China increased by $8 \mathrm{~kg} \mathrm{~N} \mathrm{ha}{ }^{-1} \mathrm{yr}^{-1}$ between the 1980 s and 2000s, from 13.2 to $21.1 \mathrm{~kg} \mathrm{~N} \mathrm{ha}^{-1} \mathrm{yr}^{-1}$, the third largest nitrogen deposition rate country next to the United States and Europe (Liu et al., 2013). According to the current trend, the global total annual nitrogen deposition will further increase to twice the current level by 2050 (Peñuelas et al., 2012). Long-term nitrogen input will lead to an excess of nitrogen in the soil and ultimately lead to increased nitrogen loss through solution leaching and trace gas emissions (Matson et al., 2002). This has been shown to affect the structure and function of ecosystems through eutrophication and acidification, leading in some cases to changes in species composition and ecosystem decline (Goulding et al., 1998; Janssens et al., 2010).

Previous studies have shown that nitrogen deposition affects the growth, reproduction and activity of soil microorganisms, changes the structure and function of soil microbial community, and affects biogeochemical cycling and nutrient availability in the soil (Liu et al., 2016). High concentrations of nitrogen can inhibit the growth of diazotrophic Azotobacter spp. (Zhang and Han, 2012) and significantly increase the abundance of ammonia-oxidizing bacteria (Ai et al., 2013). Guan et al. (2019) found that nitrogen deposition may improve the function of wetland ecosystems by increasing soil nutrient content, promoting soil enzyme activity and increasing plant yield based on a five-year nitrogen deposition experiment. However, studies of the effect of nitrogen deposition on microbial community diversity, especially in saline wetlands, are limited.

The Yellow River Delta is one of the most active deltas in the world in terms of land-ocean interactions and its geographic position makes it an important habitat for migrating birds. During the last several decades, the delta has experienced substantial changes attributed to human activities and climate change. The total nitrogen deposition rate of the YRD during the growing season (May to November) is $22.64 \mathrm{~kg} \mathrm{ha}^{-1}$, a relatively high level in China (Yu et al., 2014). Therefore, the YRD has become a unique area to study the effects of environmental change, such as nitrogen deposition, on the structure and function of wetland ecosystems. Previous research in the coastal wetland of the YRD has considered differences in soil microorganisms between differing vegetation communities (Lv et al., 2016; Zhang et al., 2017), the response of specific microbial functions, such as methane cycling to nitrogen deposition (Xiao et al., 2017), the microbial diversity of aging oil sludge (Kuang et al., 2018) and the responses of bacterial community to biological invasion (Zhang et al., 2020). However, the impact of nitrogen deposition on the regional soil microbial community diversity remains unknown. The study of the effects of nitrogen deposition on soil microorganisms in coastal wetland of the Yellow River Delta is necessary in order to comprehend the response of coastal wetland ecosystem function to human activities.

In May 2012, we built a long-term nitrogen deposition simulation experimental platform on a salinized reed wetland in the Yellow River Delta. After five consecutive years of nitrogen amendments, we applied high-throughput DNA sequencing techniques and ecophysiological analysis to determine the change in the microbial community diversity under different levels of nitrogen deposition. The objectives of the present study were (1) to characterize the molecular diversity and community composition of soil microorganisms among different levels of nitrogen deposition, and (2) to determine the relationships between specific microbial taxa and soil salinity and nutrients levels under different nitrogen deposition treatments.

\section{Materials and methods}

\subsection{Sites and environmental conditions}

The study site $\left(37^{\circ} 45^{\prime} 50^{\prime \prime} \mathrm{N}, 118^{\circ} 59^{\prime} 24^{\prime \prime} \mathrm{E}\right.$ ) (Fig. 1) and experimental design of the research station, the Yellow River Delta Ecological Research Station of Coastal Wetlands, has been described previously (Guan et al., 2019). Briefly, the annual average temperature is $11.7-12.8^{\circ} \mathrm{C}$. The annual evaporation is $1900-2400 \mathrm{~mm}$, and the annual precipitation $530-630 \mathrm{~mm}$, of which $70 \%$ is rainfall that occurs between July and September. It is typified by distinct wet (in general, July to September) and dry (in general, October to June) seasons and remains inundated throughout the wet season.

\subsection{Simulated nitrogen deposition}

The experiment began in 2012 and established 16 plots, each plot $(6 \mathrm{~m} \times 4 \mathrm{~m})$ separated by a one-meter buffer to prevent increased horizontal movement and lateral loss of $\mathrm{N}$. Four levels of $\mathrm{N}$ fertilization were set, including: control $0 \mathrm{~kg} \mathrm{~N} \mathrm{ha}^{-1} \mathrm{yr}^{-1}$ (CK); LNN, $50 \mathrm{~kg} \mathrm{~N}^{-1-}$ $\mathrm{yr}^{-1}$; MNN, $100 \mathrm{~kg} \mathrm{~N} \mathrm{ha}^{-1} \mathrm{yr}^{-1}$; HNN, $200 \mathrm{~kg} \mathrm{~N} \mathrm{ha}^{-1} \mathrm{yr}^{-1}$, and each treatment consisted of three repetitions used for microbial analysis. The selection of fertilization level was based on the current nitrogen deposition rate and the potential amount that may occur in the future (Yu et al., 2014). For each fertilization event, $\mathrm{NH}_{4} \mathrm{NO}_{3}$ was first dissolved in pure water, and then sprayed evenly on the target area. The same amount of pure water without nitrogen was sprayed in the control area. The treatments were applied once a month from May 2012 to May 2017.

\subsection{Soil sampling and physicochemical properties analysis}

Sample collection was conducted in May 2017. Subplots $(0.5 \mathrm{~m} \times 0.5 \mathrm{~m})$ were randomly selected from each treatment site. Soil samples (0-15 cm depth) were drilled with soil sampler with a diameter of $3.5 \mathrm{~cm}$. Each soil sample was cut vertically in the middle, put into a sterile self-sealing bag, and transported on ice. One half was stored in a refrigerator at $-4{ }^{\circ} \mathrm{C}$ for microbial sequencing and the other half was naturally air-dried for soil physicochemical properties analysis. The soil properties and methods of analysis were previously reported in (Guan et al., 2019) and are analyzed here in conjunction with new microbial data. The soil properties included soil salinity, soil total nitrogen (TN), total carbon (TC) and total organic carbon (TOC), soil nitrate $\left(\mathrm{NO}_{3}^{-}-\mathrm{N}\right)$ and ammonium $\left(\mathrm{NH}_{4}^{+}-\mathrm{N}\right)$, and soil available phosphorus extractable by sodium bicarbonate (AP).

\subsection{Microbial diversity analysis}

Total genomic DNA from sediment samples was extracted using $\mathrm{CTAB} / \mathrm{SDS}$ method. DNA concentration and purity were monitored on $1 \%$ agarose gels. According to the concentration, DNA was diluted to $1 \mathrm{ng} \mu \mathrm{L}^{-1}$ using sterile water. The16S rRNA V4-V5 region was amplified using barcoded 515F/907R primers (Biddle et al., 2008; Jing et al., 2015). Briefly, these primers cover one or several high-variation regions that are sequenced and identified. All PCR reactions were carried out with Phusion ${ }^{\circledR}$ High-Fidelity PCR Master Mix (New England Biolabs). Paired-end sequencing of PCR amplicons was performed on an Illumina HiSeq 2500 sequencer (Illumina, San Diego, CA, USA). Briefly, the PCR reaction mixture of $37.5 \mu \mathrm{L}$ contained the following components: $25 \mu \mathrm{L}$ PCR Master Mix with GC Buffer (New England Biolabs, United States), $1.0 \mu \mathrm{L}$ of $10 \mu \mathrm{M}$ forward and reverse primers (each), $2.5 \mu \mathrm{L}$ of total genomic DNA (5-10 ng) and $8.0 \mu \mathrm{L}$ of $\mathrm{H}_{2} \mathrm{O}$. The amplification program consisted of $5 \mathrm{~min}$ at $95^{\circ} \mathrm{C}$ for initial denaturation followed by 34 cycles of $94{ }^{\circ} \mathrm{C}$ for $1 \mathrm{~min}, 57^{\circ} \mathrm{C}$ for $45 \mathrm{~s}, 72^{\circ} \mathrm{C}$ for $1 \mathrm{~min}$ and a final $72{ }^{\circ} \mathrm{C}$ for $10 \mathrm{~min}$ for extension and $16{ }^{\circ} \mathrm{C}$ for $5 \mathrm{~min}$ for cooling. The PCR products were separated in $2 \%$ agarose gel and stained with 


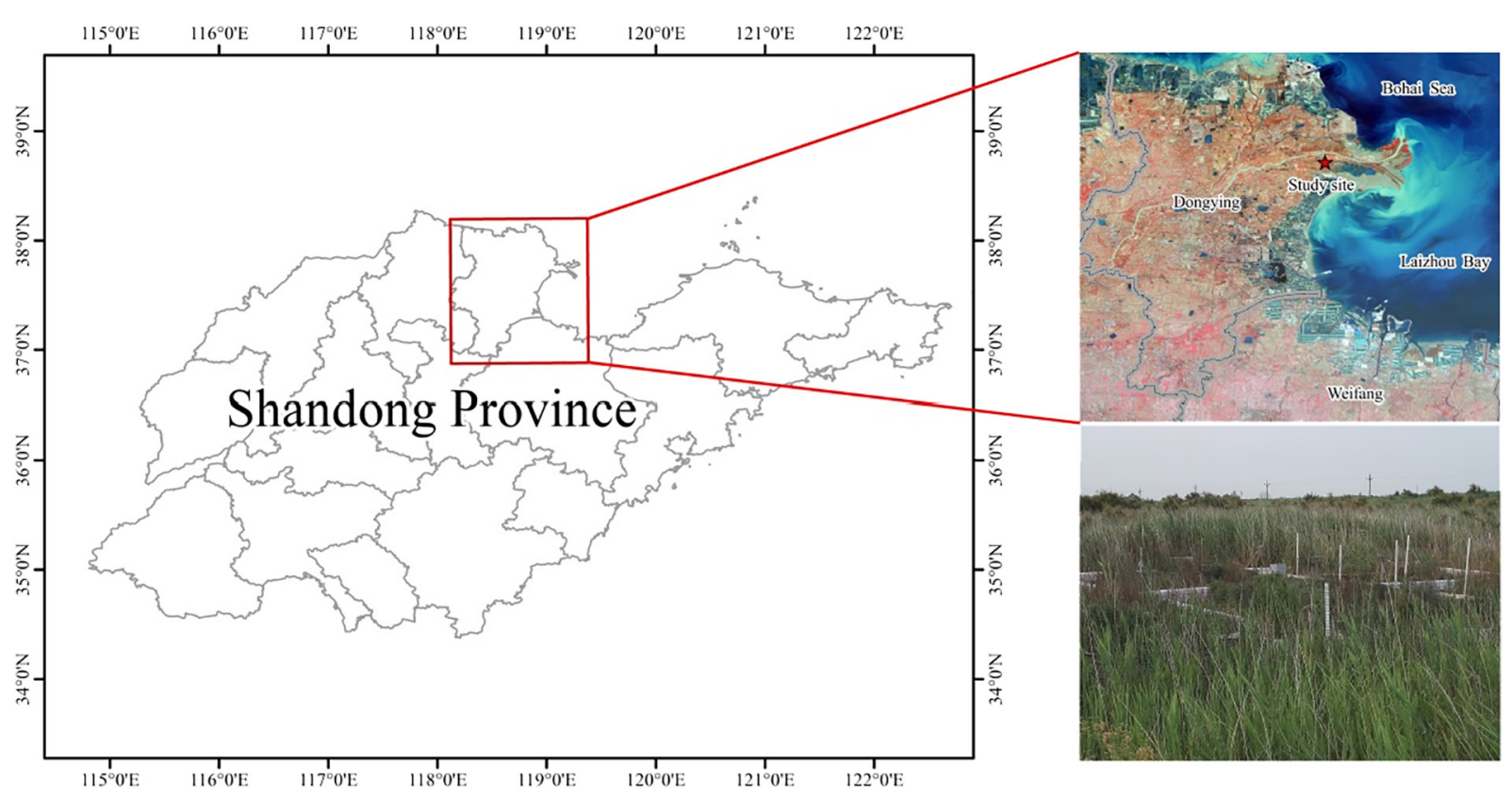

Fig. 1. Location of the Yellow River Delta and the experimental platform.

ethidium bromide. The PCR products were then purified with Qiagen Gel Extraction Kit (Qiagen, Germany). The bar-coded PCR products from all samples were combined in equimolar amounts, then prepared for sequencing using the TruSeq ${ }^{\mathrm{TM}}$ DNA Sample Preparation Kit and sequenced using the HiSeq PE250 (Illumina) following the manufacturer's protocols.

The sequencing reads were demultiplexed, forward and reverse reads were combined, then barcode and primer sequences were removed from all the sample data and using FLASH (Magoč and Salzberg, 2011). The sequences were processed through strict quality filtering using the QIIME (version 1.7.0; Caporaso et al., 2010) script split_libraries_fastq.py with options to truncate from the first lowquality base site (where the quality threshold is $\leq 19$ for the set length of 3 ) and filter out sequences with a continuous high-quality base length of $<75 \%$. The chimeric sequences were detected and removed using Vsearch (Rognes et al., 2016), giving the final effective sequences.

Then the Uparse (Edgar, 2013) software (version 7.0.1001, http:// www.drive5.com/uparse/) was used to cluster the effective sequences into operational taxonomic units (OTUs) at $97 \%$ similarity and select the highest frequency sequence as the representative sequence. The taxonomic annotation of the OTUs was carried out with Mothur (Schloss et al., 2009) and the SSU rRNA reference sequences from the SILVA (Pruesse et al., 2007) database (version 132; http://www. arb-silva.de/) with the threshold value set at $0.8-1$. The community composition of the samples was analyzed at multiple taxonomic levels: kingdom, phylum, class, order, family, genus, species. The number of sequences was normalized across all samples by rarefaction using the number corresponding to the sample with the least sequences (43896). All sequences from this study have been deposited at GenBank with accession number SRP278006.

\subsection{Statistical analysis}

The complexity of species diversity, or alpha diversity, was analyzed by the Shannon and Simpson metrics. The indices were calculated with QIIME (version 1.9.1; Caporaso et al., 2010) and displayed with R software by heatmap and boxplot (version 2.15.3; http://www.r-project. org).

Differences among treatments were tested using Fisher's LSD method and statistically significant correlations between taxa and environmental variables were identified using Pearson correlation. Redundancy analyses (RDA) were conducted on environment variables with microbial diversity and specific bacteria separately. All acquired data were represented by the average of three replicate measurements and standard error. Significance was tested at the 5\% level. LSD and correlation analyses were done with SPSS 24.0. RDA analyses were conducted with CANOCO 4.5 software.

\section{Results}

\subsection{Effects of $N$ addition on microbial diversity and community composition}

At the phylum level, the microbial community was dominated by Proteobacteria (36.2\%) and Chloroflexi (21.6\%), followed by Bacteroidetes (12.0\%), Acidobacteria (8.6\%), Gemmatimonadetes (6.7\%), Planctomycetes (5.9\%), Actinobacteria (4.6\%), Firmicutes (2.2\%), Chlorobi (1.1\%) and Verrucomicrobia (1.1\%) (Fig. 2). The relative abundance of Chloroflexi increased significantly under the HNN treatment $(P=0.002)$. The relative abundance of Firmicutes increased under the MNN treatment and decreased under HNN, and the difference between the MNN and HNN treatment was significant $(P=0.021)$. Compared with the control group, the relative abundance of Chlorobi significantly decreased under the treatment of $\operatorname{LNN}(P=0.008)$ and $\operatorname{HNN}(P=0.013)$. The relative abundance of Verrucomicrobia decreased significantly under the treatment of $\operatorname{MNN}(P=0.024)$ and $\operatorname{HNN}(P=0.035)$.

For the most abundant phylum Proteobacteria, we considered the relative abundance distributions at the subphyla level (Fig. 3). The primary subphyla were the Deltaproteobacteria (34.3\%), Gammaproteobacteria (30.5\%), Alphaproteobacteria (24.4\%), and Betaproteobacteria (10.4\%). The relative abundance of Betaproteobacteria and Gammaproteobacteria significantly increased $(P=0.049, \mathrm{HNN})$ and decreased $(P=0.027, \mathrm{HNN})$ under different nitrogen deposition gradients, respectively.

The relative abundance of the most abundant 35 groups at the genus level is illustrated in Fig. 4 with a clustered heat map. Compared with the control group, Halomonas $(P=0.042)$, Urania-1B19_marine_sediment_group $(P=0.036)$, Bacillus $(P=0.001)$ and Spirochaeta_2 $(P=0.001)$ showed significant differences under HNN treatment. Bacillus $(P=0.041)$, Alterococcus $(P=0.016)$ were significantly different between LNN and HNN treatment; Deferrisoma $(P=$ 


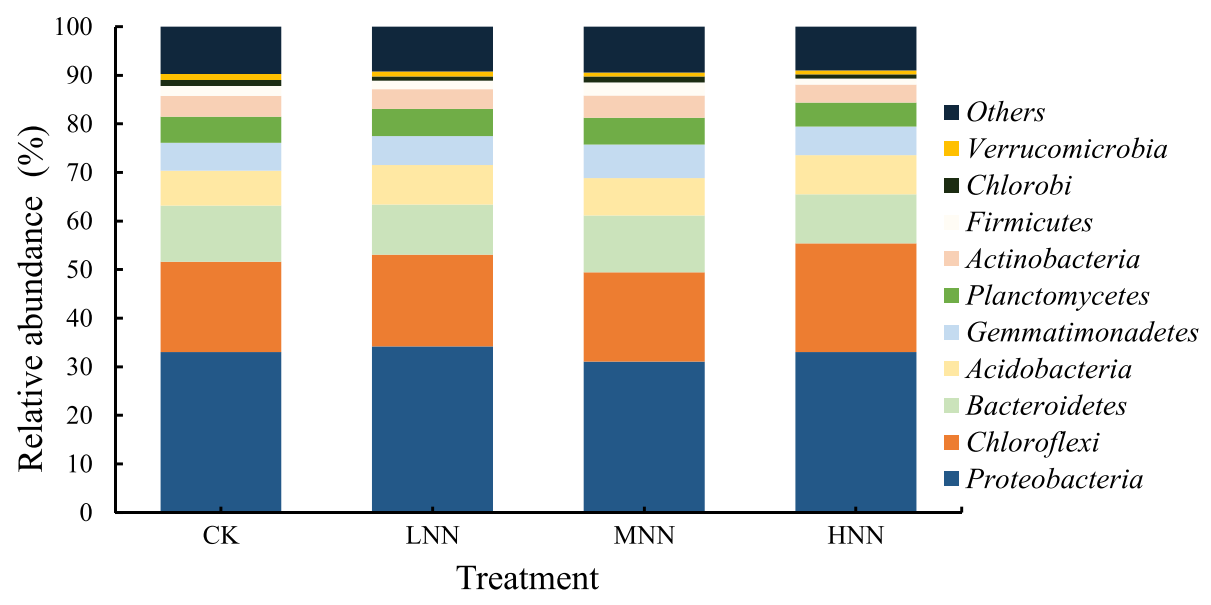

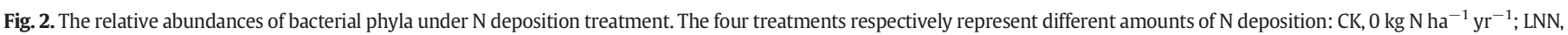
$50 \mathrm{~kg} \mathrm{~N} \mathrm{ha}^{-1} \mathrm{yr}^{-1}$; MNN, $100 \mathrm{~kg} \mathrm{~N} \mathrm{ha}^{-1} \mathrm{yr}^{-1}$; HNN, $200 \mathrm{~kg} \mathrm{~N} \mathrm{ha}^{-1} \mathrm{yr}^{-1}$.

$0.034)$ and Spirochaeta_2 $(P=0.007)$ showed significant differences between the control and the MNN treatment.

The Shannon and Simpson indices were used to estimate and compare the alpha diversity of bacterial communities among the $\mathrm{N}$ deposition treatments. The Shannon and Simpson indices significantly decreased with the HNN treatment (Shannon, $P=0.026$; Simpson, $P=0.000$ ) (Fig. 5; Supporting Materials Table 1).

3.2. The relationship between soil microorganisms and soil physicochemical properties under $N$ addition

Correlation analysis was conducted between phyla (Chloroflexi, Verrucomicrobia, Chlorobi, Firmicutes), Proteobacteria subphyla (Betaproteobacteria, Gammaproteobacteria) and three genera (Bacillus, Nitrococcus, Halomonas) with significant changes in relative abundance and soil physicochemical properties. The relative abundance of Bacillus and Halomonas showed a decreasing trend with greater nitrogen deposition treatments. With HNN treatment Bacillus was significantly less abundant $(P=0.01)$ than in the three treatments and Halomonas was significantly less abundant $(P=0.042)$ than in the control group. The relative abundance of Nitrococcus significantly increased $(P=0.04)$ under the MNN treatment (Fig. 6).

Correlation analysis showed that the relative abundance of Chloroflexi was positively correlated with $\mathrm{NH}_{4}^{+}-\mathrm{N}(r=0.584$, $P<0.05)$. The Verrucomicrobia was negatively correlated with AP $(r=-0.602, P<0.05), \mathrm{NH}_{4}^{+}-\mathrm{N}(r=-0.645, P<0.05), \mathrm{NO}_{3}^{-}-\mathrm{N}(r=$ $-0.591, P<0.05)$, TN $(r=-0.631, P<0.05)$ and TC $(r=-0.614$, $P<0.05)$ concentrations in soil. The relative abundance of Gammaproteobacteria was positively correlated with salt content $(r=$ $0.780, P<0.01$ ). The relative abundance of Bacillus was positively correlated with $\mathrm{NH}_{4}^{+}-\mathrm{N}(r=0.635, P<0.05)$ concentrations in soil. The relative abundance of Nitrococcus was positively correlated with $\mathrm{NH}_{4}^{+}-\mathrm{N}$ $(r=-0.666, P<0.01)$, TN $(r=-0.745, P<0.01)$ and TC $(r=$ $-0.796, P<0.01)$ concentrations in soil.

A RDA of soil physicochemical properties and the Shannon and Simpson indices of microbial diversity explained $95.2 \%$ of the variation in axes 1 (Fig. 7). Pearson correlation analysis showed that $\mathrm{NH}_{4}^{+}-\mathrm{N}$ and $\mathrm{NO}_{3}^{-}-\mathrm{N}$ concentration significantly affected Shannon index $(P<0.01)$, and $\mathrm{NH}_{4}^{+}-\mathrm{N}$ was also negatively correlated with Simpson index $(P<0.05$; Supporting Materials Table 2$)$.

\section{Discussion}

Microorganisms have many roles in the ecological processes of the YRD (Yu et al., 2012). They represent an important component of the soil ecosystem and can be a valuable mechanism for wetland restoration (Ma et al., 2017; Wang et al., 2010). Previous studies have found that microorganisms can work cooperatively with plants (Bentivenga and Hetrick, 1992), reduce the toxicity of heavy metals to plants (Bissonnette et al., 2010), affect plant competition and plant coexistence

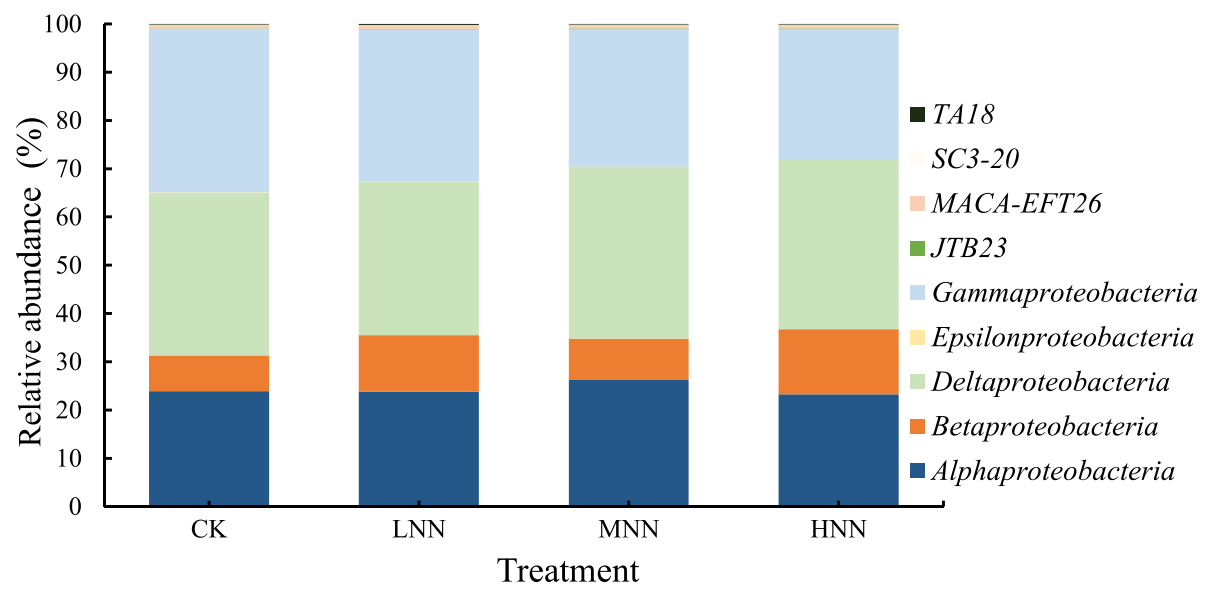

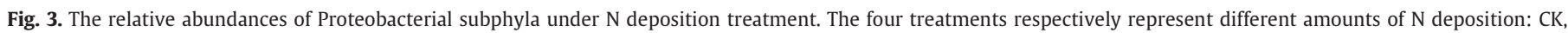
0 kg N ha ${ }^{-1} \mathrm{yr}^{-1}$; LNN, $50 \mathrm{~kg} \mathrm{~N} \mathrm{ha}^{-1} \mathrm{yr}^{-1}$; MNN, $100 \mathrm{~kg} \mathrm{~N} \mathrm{ha}^{-1} \mathrm{yr}^{-1}$; HNN, $200 \mathrm{~kg} \mathrm{~N}^{-1} \mathrm{yr}^{-1}$. 


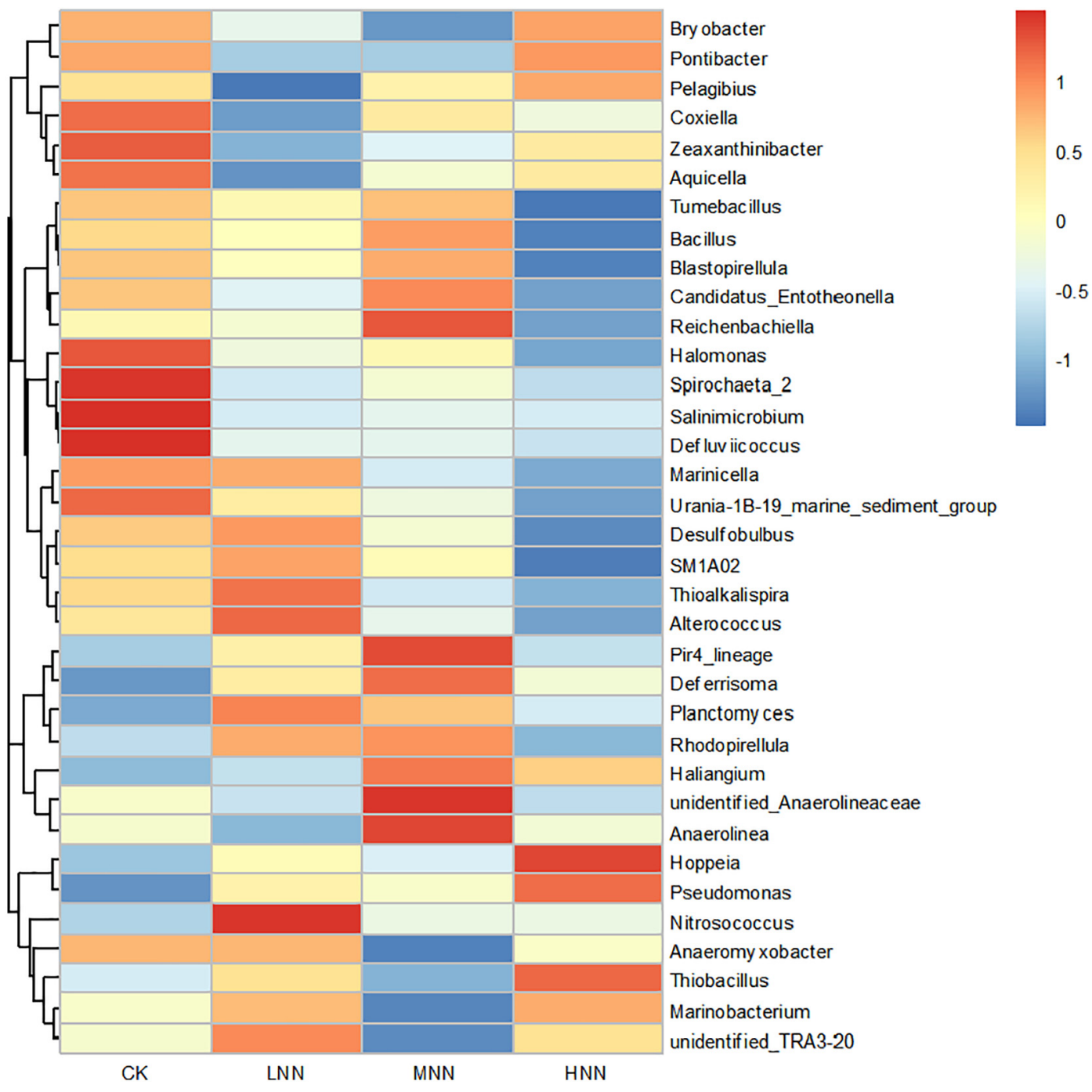

Fig. 4. The relative abundance of the first 35 most abundant genera was made into a clustering heat map. The four treatments respectively represent different amounts of $\mathrm{N}$ deposition: $\mathrm{CK}$, $0 \mathrm{~kg} \mathrm{~N} \mathrm{ha}^{-1} \mathrm{yr}^{-1}$; LNN, $50 \mathrm{~kg} \mathrm{~N} \mathrm{ha}^{-1} \mathrm{yr}^{-1}$; MNN, $100 \mathrm{~kg} \mathrm{~N} \mathrm{ha}^{-1} \mathrm{yr}^{-1}$; HNN, $200 \mathrm{~kg} \mathrm{~N} \mathrm{ha}^{-1} \mathrm{yr}^{-1}$.

(a)

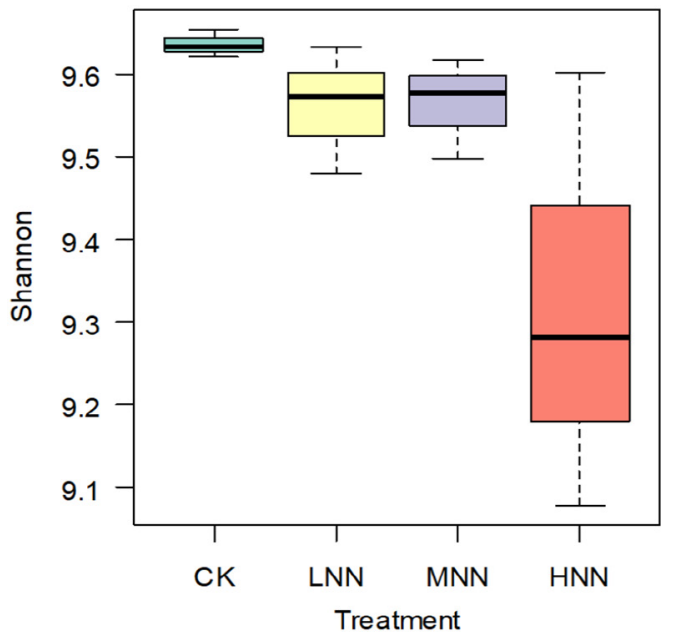

(b)

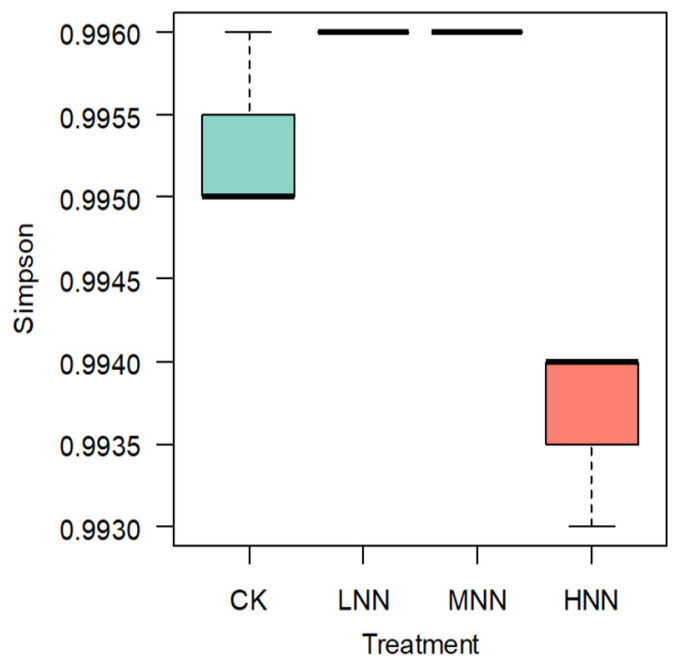

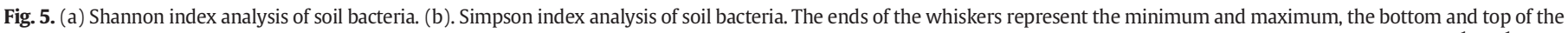

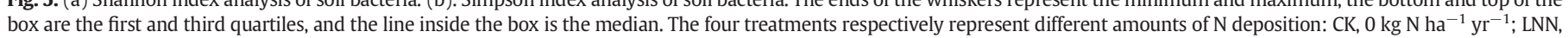
$50 \mathrm{~kg} \mathrm{~N} \mathrm{ha}^{-1} \mathrm{yr}^{-1}$; MNN, $100 \mathrm{~kg} \mathrm{~N} \mathrm{ha}^{-1} \mathrm{yr}^{-1}$; HNN, $200 \mathrm{~kg} \mathrm{~N} \mathrm{ha}^{-1} \mathrm{yr}^{-1}$. 

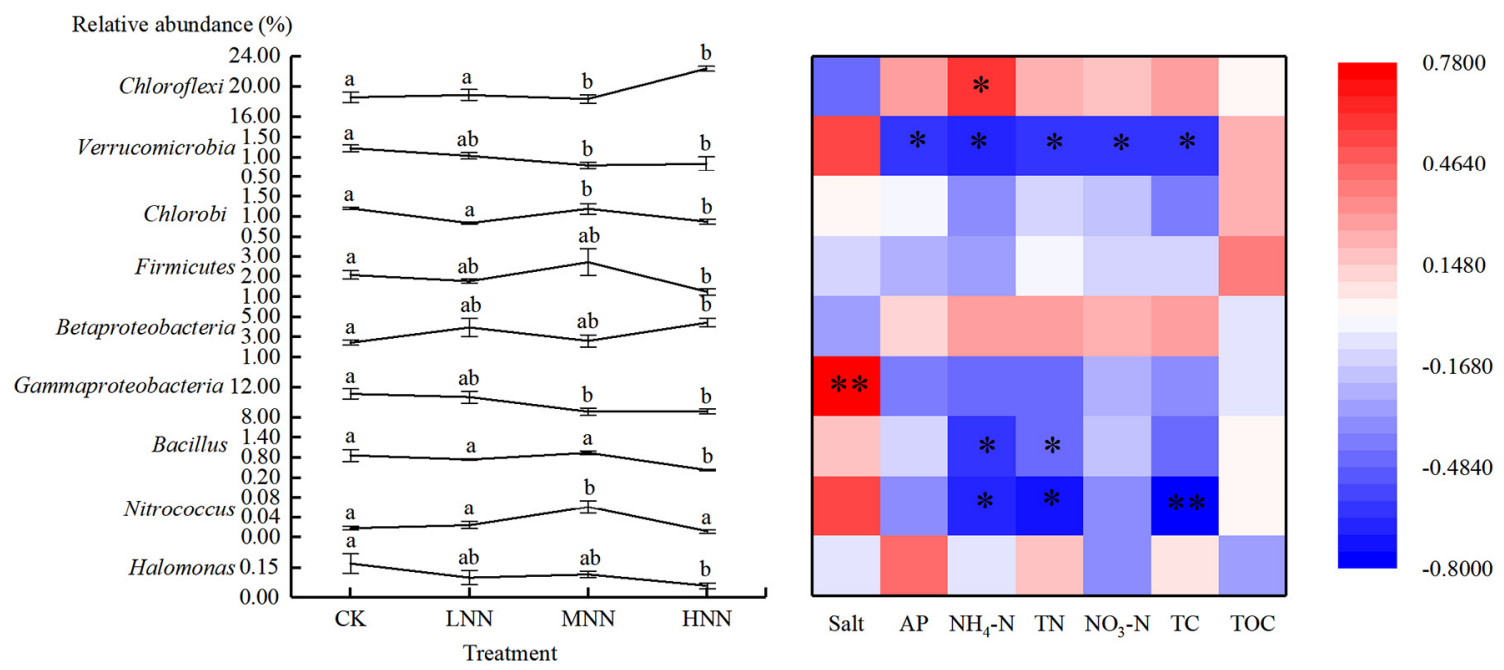

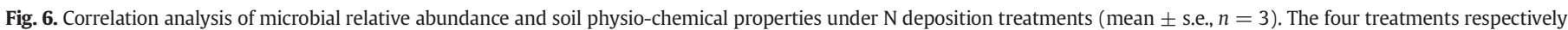

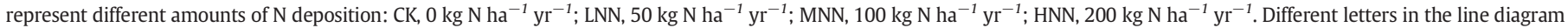

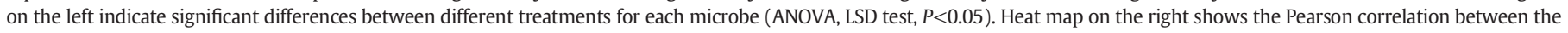
relative abundance of the microorganisms and environmental variables, ${ }^{*}, P<0.05$; ${ }^{* *}, P<0.01$.

(Hetrick et al., 1989), and thus influence the structure and species diversity of plant communities.

Under different $\mathrm{N}$ deposition treatments, combined with soil physical and chemical indexes and microbial diversity analysis, the quantities of $\mathrm{NO}_{3}^{-}-\mathrm{N}, \mathrm{NH}_{4}^{+}-\mathrm{N}$, TN and TC were found the most important factors affecting soil bacterial diversity. High levels of $\mathrm{N}$ in the HNN treatment were associated with a significant decrease in the microbial diversity compared with the other treatments. This decrease in diversity may be due to soil acidification resulting from the long-term $\mathrm{N}$ deposition in the supersaturated state (Chung et al., 2010). On the other hand, long-term $\mathrm{N}$ deposition may also decrease available organic matter of soil microorganisms, changing the use of microbial substrate model (Wallander, 1995), reducing the microbial utilization of carbon sources (Bowden et al., 2004), reducing the microbial activity and diversity (Liu et al., 2016). A decrease in microbial diversity with high $\mathrm{N}$ deposition was also found in previous studies. Based on a meta-analysis of data from 198 sampling points, the researchers found that nitrogen deposition reduced the soil microbial diversity of all ecosystem types to varying degrees (Wang et al., 2018). As $\mathrm{N}$ deposition rates increase, the alteration of ecosystem function resulting from the loss of rare species and microbial diversity might have profound feedback on global climate change (Cui et al., 2017; Liu et al., 2016). Other researchers have shown that long-term $\mathrm{N}$ deposition can reduce soil respiration rate, enzyme activity, and change the biomass ratio of fungi and bacteria (Frey et al., 2004; DeForest et al., 2004). Under a high N environment, bacteria may be at a disadvantage in competition with fungi. Liu et al. (2016) found that a high level of $\mathrm{N}$ deposition would affect the reproduction

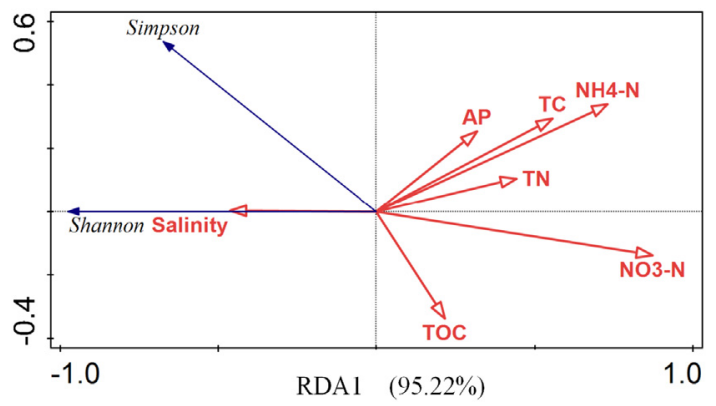

Fig. 7. Redundancy analysis (RDA) of soil physicochemical properties and the Shannon and Simpson indices of microbial diversity under $\mathrm{N}$ deposition treatments. and activity of soil microorganisms, inhibit their growth, change the structure and function of soil microbial community, and affect decomposition and nutrient availability in soil.

The three bacterial genera identified in this study with significant correlations to $\mathrm{N}$ have different life history strategies. The relative abundance of Halomonas, a halophile, was negatively correlated to N. The reason for the decrease in relative abundance may be that the addition of $\mathrm{N}$ can indirectly reduce the salt content of the soil surface (Guan et al., 2019). Both Bacillus and Nitrococcus participate in the denitrification process. Nitrococcus is an aerobic bacterium, while Bacillus can survive under aerobic and anaerobic conditions. Their relative abundance increases or decreases with the availability of nitrogen. It may be that $\mathrm{N}$ deposition directly or indirectly leads to the transformation of life cycle strategies of major microorganisms, so their response to nitrogen deposition is inconsistent (Fierer et al., 2012).

Previous study demonstrated that the change of soil microbial community composition was closely related to soil nutrients (Zhang et al., 2019). In our study, the dominant bacteria groups were Proteobacteria, and Bacteroides, at the phylum level, even at different nitrogen levels. This indicated that some phyla of soil microorganisms had certain adaptability (Zhao et al., 2020; Huang et al., 2020a, 2020b). However, the abundance of Firmicutes, Chlorobacteria and Verrucomicrobia were significantly decreased by nitrogen addition. Three phyla are known to be important participants in the carbon and nitrogen cycles (Buchanan and Arnon, 1990; Wahlund and Madigan, 1993; Wahlund and Tabita, 1997), and high concentration of nitrogen deposition inhibits their activity. Nitrogen deposition increases the content of $\mathrm{NO}_{3}^{-}$$\mathrm{N}$ and number of free hydrogen ions in soil (Chen et al., 2013), thus increasing the relative abundance of Chloroflexi, a heterotrophic phylum growing under acidic conditions (Hug et al., 2013). In addition, Pearson correlation analysis showed that $\mathrm{TN}, \mathrm{TC}$ and $\mathrm{NO}_{3}^{-}-\mathrm{N}$ were negatively correlated with Firmicutes, Chlorobi and Verrucomicrobia, and positively correlated with Acidobacteria. The former may be at a disadvantage in the competition under high nutrient conditions (Fierer et al., 2012). The decrease in the relative abundance of Gammaproteobacteria with nitrogen addition may be due to the presence of halophilic bacteria under its subphylum, such as Thialkalivibrio Halophilus, Pseudoalteromonas, etc. (Banciu et al., 2004; Novikova et al., 2013). Correlation analysis also showed that the relative abundance of Gammaproteobacteria was significantly correlated with salinity content, consistent with the results of a previous study (Korlević et al., 2016). However, nitrogen deposition increased the relative abundance of Betaproteobacteria, perhaps because nitrogen addition affected the nitrification rate of some bacteria under 
its subphyla (Ma et al., 2018), and it showed a positive correlation with salinity content.

\section{Conclusions}

In general, nitrogen deposition significantly reduced microbial diversity in the coastal wetland of the YRD. Statistical analysis showed that $\mathrm{TN}, \mathrm{TC}$ and $\mathrm{NO}_{3}^{-}-\mathrm{N}$ had a large influence on the microbial community, while $\mathrm{NH}_{4}^{+}-\mathrm{N}$ had a great impact on some specific microbial groups such as Nitrococcus and Bacillus. Our research provides a basis for understanding the soil microbial responses to nitrogen deposition and the relationship between the soil microbial community and soil physiochemical characteristics in a salinized wetland of the YRD. These results provide theoretical support for understanding the impact of environmental changes on microbial communities in the coastal wetland ecosystem.

\section{Declaration of competing interest}

The authors have declared that no competing interests exist.

\section{Acknowledgements}

This work was financially supported by the National Key Research and Development Program of China (2017YFC0505901), the Strategic Priority Research Program of the Chinese Academy of Sciences (XDA23050202) and the National Natural Science Foundation of China (U1806218 and 41871091). We thank the Yellow River Delta Ecology Research Station of Coastal Wetland, Chinese Academy of Sciences, for the help with field work.

\section{Appendix A. Supplementary data}

Supplementary data to this article can be found online at https://doi. $\operatorname{org} / 10.1016 / j$.scitotenv.2020.143825.

\section{References}

Ai, C., Liang, G., Sun, J., Wang, X., He, P., Zhou, W., 2013. Different roles of rhizosphere effect and long-term fertilization in the activity and community structure of ammonia oxidizers in a calcareous fluvo-aquic soil. Soil Biol. Biochem. 57, 30-42.

Banciu, H., Sorokin, D.Y., Galinski, E.A., Muyzer, G., Kleerebezem, R., Kuenen, J.G., 2004. Thialkalivibrio halophilus sp. nov. a novel obligately chemolithoautotrophic, facultatively alkaliphilic, and extremely salt-tolerant, sulfur-oxidizing bacterium from a hypersaline alkaline lake. Extremophiles 8 (4), 325-334.

Bentivenga, S.P., Hetrick, B.A.D., 1992. Seasonal and temperature effects on mycorrhizal activity and dependence of cool- and warm-season tallgrass prairie grasses. Can. J. Bot. 70 (8), 1596-1602.

Biddle, J.F., Fitz-Gibbon, S., Schuster, S.C., Brenchley, J.E., House, C.H., 2008. Metagenomic signatures of the Peru margin subseafloor biosphere show a genetically distinct environment. Proc. Natl. Acad. Sci. U. S. A. 105, 10583-10588.

Bissonnette, L., Starnaud, M., Labrecque, M., 2010. Phytoextraction of heavy metals by two Salicaceae clones in symbiosis with arbuscular mycorrhizal fungi during the second year of a field trial. Plant Soil 332, 55-67.

Bowden, R.D., Davidson, E., Savage, K., Arabia, C., Steudler, P., 2004. Chronic nitrogen additions reduce total soil respiration and microbial respiration in temperate forest soils at the Harvard Forest. For. Ecol. Manag. 196 (1), 43-56.

Buchanan, B.B., Arnon, D.I., 1990. A reverse Krebs cycle in photosynthesis - consensus at last. Photosynth. Res. 24, 47-53.

Caporaso, J.G., Kuczynski, J., Stombaugh, J., Bittinger, K., Bushman, F.D., Costello, E.K., Fierer, N., Peña, A.G., Goodrich, J.K., Gordon, J.I., Huttley, G.A., Kelley, S.T., Knights, D., Koenig, J.E., Ley, R.E., Lozupone, C.A., McDonald, D., Muegge, B.D., Pirrung, Meg., Reeder, J., Sevinsky, J.R., Turnbaugh, P.J., Walters, W.A., Widmann, J., Yatsunenko, T., Zaneveld, J., Knight, 2010. QIIME allows analysis of high-throughput community sequencing data. Nat. Methods 7 (5), 335-336.

Chen, D., Lan, Z., Bai, X., Grace, J.B., Bai, Y.F., 2013. Evidence that acidification-induced declines in plant diversity and productivity are mediated by changes in belowground communities and soil properties in a semi-arid steppe. J. Ecol. 101, 1322-1334.

Chung, H., Zak, D.R., Reich, P.B., Ellsworth, D.S., 2010. Plant species richness, elevated $\mathrm{CO}_{2}$, and atmospheric nitrogen deposition alter soil microbial community composition and function. Glob. Chang. Biol. 13 (5), 980-989.
Cui, J., Wang, J., Xu, J., Xu, C., Xu, X., 2017. Changes in soil bacterial communities in an evergreen broad-leaved forest in East China following 4 years of nitrogen addition. J. Soils Sediments 17, 2156-2164.

DeForest, J.L., Zak, D.R., Pregitzerc, K.S., Burton, A.J., 2004. Atmospheric nitrate deposition and the microbial degradation of cellobiose and vanillinina northern hard woodforest. Soil Biol. Biochem. 36, 965-971.

Edgar, R.C., 2013. UPARSE: highly accurate OTU sequences from microbial amplicon reads. Nat. Methods 10 (10), 996-998.

Fierer, N., Lauber, C.L., Ramirez, K.S., Zaneveld, J., Bradford, M.A., Knight, R., 2012. Comparative metagenomics, phylogenetic and physiological analyses of soil microbial communities across nitrogen gradients. ISME J 6 (5), 1007-1017.

Frey, S.D., Knorr, M., Parrent, J.L., Simpson, R.T., 2004. Chronic nitrogen enrichment affects the structure and function of the soil microbial community in temperate hardwood and pine forests. For. Ecol. Manag. 196 (1), 159-171.

Goulding, K.W.T., Bailey, N.J., Bradbury, N.J., Hargreaves, P., Howe, M., Murphy, D.V., Poulton, P.R., Willison, T.W., 1998. Nitrogen deposition and its contribution to nitrogen cycling and associated soil processes. New Phytol. 139, 49-58.

Guan, B., Xie, B., Yang, S., Hou, A., Chen, M., Han, G., 2019. Effects of five years' nitrogen deposition on soil properties and plant growth in a salinized reed wetland of the Yellow River Delta. Ecol. Eng. 136, 160-166.

Hetrick, B.A.D., Wilson, G.W.T., Hartnett, D.C., 1989. Relationship between mycorrhizal dependence and competitive ability of two tallgrass prairie grasses. Can. J. Bot. 67, 2608-2615.

Huang, L., Bai, J., Wen, X., Zhang, G., Zhang, C., Cui, B., Liu, X., 2020a. Microbial resistance and resilience in response to environmental changes under the higher intensity of human activities than global average level. Glob. Chang. Biol. 26, 2377-2389.

Huang, L., Zhang, G., Bai, J., Xia, Z., Wang, W., Jia, J., Wang, X., Liu, X., Cui, B., 2020b. Desalinization via freshwater restoration highly improved microbial diversity, cooccurrence patterns and functions in coastal wetland soils. Sci. Total Environ. https://doi.org/10.1016/j.scitotenv.2020.142769.

Hug, L.A., Castelle, C.J., Wrighton, K.C., Thomas, B.C., Sharon, I., Frischkorn, K.R., Williams, K.H., Tringe, S.G., Banfield, J.F., 2013. Community genomic analyses constrain the distribution of metabolic traits across the Chloroflexi phylum and indicate roles in sediment carbon cycling. Microbiome 1, 1-17.

Janssens, I.A., Dieleman, W., Luyssaert, S., Subke, J.A., Reichstein, M., Ceulemans, R., Ciais, P., Dolman, A.J., Grace, J., Matteucci, G., Papale, D., Piao, S.L., Schulze, E.-D., Tang, J. Law, B.E., 2010. Reduction of forest soil respiration in response to nitrogen deposition. Nat. Geosci. 3 (5), 315-322.

Jing, X., Sanders, N.J., Shi, Y., Chu, H.Y., Classen, A.T., Zhao, K., Chen, L.T., Shi, Y., Jiang, Y.X., He, J.S., 2015. The links between ecosystem multifunctionality and above- and belowground biodiversity are mediated by climate. Nat. Commun. 6, 1-8.

Korlević, M., Šuupraha, L., Ljubešić, Z., Henderiks, J., Ciglenečki, I., Dautovićd, J., Orlić, S., 2016. Bacterial diversity across a highly stratified ecosystem: a salt-wedge mediterranean estuary. Syst. Appl. Microbiol. 39, 398-408.

Kuang, S., Su, Y., Wang, H., Yu, W., Lang, Q., Matangi, R., 2018. Soil microbial community structure and diversity around the aging oil sludge in Yellow River Delta as determined by high-throughput sequencing. Archaea 2018, 1-10.

Liu, X., Zhang, Y., Han, W., Tang, A., Shen, J., Cui, Z., Vitousek, P., Erisman, J.W., Goulding, K., Christie, P., Fangmeier, A., Zhang, F., 2013. Enhanced nitrogen deposition over China. Nature 494 (7438), 459-462.

Liu, C., Dong, Y., Sun, Q., Jiao, R., 2016. Soil bacterial community response to short-term manipulation of the nitrogen deposition form and dose in a Chinese fir plantation in Southern China. Water Air Soil Pollut. 227 (12), 447.

Lv, X., Ma, B., Yu, J., Chang, S.X., Xu, J., Li, Y., Wang, G., Han, G., Guan, B., Chu, X., 2016. Bacterial community structure and function shift along a successional series of tidal flats in the Yellow River Delta. Sci. Rep. 6, 36550.

Ma, Z., Zhang, M., Xiao, R., Cui, Y., Yu, F., 2017. Changes in soil microbial biomass and community composition in coastal wetlands affected by restoration projects in a Chinese delta. Geoderma 289 (289), 124-134.

Ma, Y., Tao, W., Liu, J., Liu, C., Li, J., Liu, J., 2018. Response of ammonia-oxidizing betaproteobacteria to short-term fertilization in a salt marsh in China. J. Oceanol. Limn. 36 (12), 351-361.

Magoč, T., Salzberg, S., 2011. FLASH: fast length adjustment of short reads to improve genome assemblies. Bioinformatics 27 (21), 2957-2963.

Matson, P., Lohse, K.A., Hall, S.J., 2002. The globalization of nitrogen deposition: consequences for terrestrial ecosystems. Ambio 31 (2), 113-119.

Novikova, O.D., Khomenko, V.A., Frolova, G.M., Likhatskaya, G.N., Romanenko, L.A., Portnyagina, O.Yu., Kuznetsova, S.M., Solovyeva, T.F., 2013. Porins from marine bacteria of the genus pseudoalteromonas (gammaproteobacteria: pseudoalteromonadaceae). Russ. J. Mar. Biol. 39, 58-64

Peñuelas, J., Sardans, J., Rivas-Ubach, A., Janssens, I.A., 2012. The human-induced imbalance between C, N and P in earth's life system. Glob. Chang. Biol. 18 (1), 3-6.

Pruesse, E., Quast, C., Katrin, Knittel, Fuchs, B., Ludwig, W., Peplies, J., Glöckner, F., 2007. SILVA: comprehensive databases for quality checked and aligned ribosomal RNA sequence data compatible with ARB. Nucleic Acids Res. 35 (21), 7188-7196.

Rognes, T., Flouri, T., Nichols, B., Quince, C., Mahé, F., 2016. Vsearch: a versatile open source tool for metagenomics. Peer J. 4 (10), e2584.

Schloss, P.D., Westcott, S.L., Ryabin, T., Hall, J.R., Hartmann, M., Hollister, E.B., Lesniewski, R.A., Oakley, B.B., Parks, D.H., Robinson, C.J., Sahl, J.W., Stres, B., Thallinger, G.G., Van Horn, D.J., Weber, C.F., 2009. Introducing mothur: open-source, platformindependent, community-supported software for describing and comparing microbial communities. Appl. Environ. Microbiol. 75 (23), 7537-7541.

Vitousek, P.M., Aber, J.D., Howarth, R.W., Likens, G.E., Matson, P.A., Schindler, D.W., Schlesinger, W.H., Tilman, D.G., 1997. Human alteration of the global nitrogen cycle: sources and consequences. Ecol. Appl. 7 (3), 737-750. 
Wahlund, T.M., Madigan, M.T., 1993. Nitrogen-fixation by the thermophilic green sulfur bacterium Chlorobium tepidum. J. Bacteriol. 175, 474-478.

Wahlund, T.M., Tabita, F.R., 1997. The reductive tricarboxylic acid cycle of carbon dioxide assimilation: initial studies and purification of ATP-citrate lyase from the green sulfur bacterium Chlorobium tepidum. J. Bacteriol. 179, 4859-4867.

Wallander, H., 1995. A new hypothesis to explain allocation of dry matter between mycorrhizal fungi and pine seedlings in relation to nutrient supply. Plant Soil 168-169 (1), 243-248.

Wang, Z., Xin, Y., Gao, D., Li, F., Morgan, J., Xing, B., 2010. Microbial community characteristics in a degraded wetland of the Yellow River Delta. Pedosphere (4), 266-278.

Wang, C., Liu, D., Bai, E., 2018. Decreasing soil microbial diversity is associated with decreasing microbial biomass under nitrogen addition. Soil Biol. Biochem. 120, $126-133$.

Xiao, L., Xie, B., Liu, J., Zhang, H., Han, G., Wang, O., Liu, F., 2017. Stimulation of long-term ammonium nitrogen deposition on methanogenesis by Methanocellaceae in a coastal wetland. Sci. Total Environ. 595, 337-343.

Yu, Y., Wang, H., Liu, J., Wang, Q., Shen, T., Guo, W., Wang, R., 2012. Shifts in microbial community function and structure along the successional gradient of coastal wetlands in Yellow River estuary. Eur. J. Soil Biol. 49, 12-21.
Yu, J., Ning, K., Li, Y., Du, S., Han, G., Xing, Q., Wu, H., Wang, G., Gao, Y., 2014. Wet and dry atmospheric depositions of inorganic nitrogen during plant growing season in the coastal zone of Yellow River Delta. Sci. World J. 2014 (3), 949213.

Zhang, M., Han, G., 2012. Nitrogen deposition alters soil chemical properties and bacterial communities in the Inner Mongolia grassland. J. Environ. Sci. 24 (8), 1483-1491.

Zhang, H., Zheng, S., Ding, J., Wang, O., Liu, F., 2017. Spatial variation in bacterial community in natural wetland-river-sea ecosystems. J. Basic Microbiol. 57 (6), 536-546.

Zhang, G., Bai, J., Jia, J., Wang, W., Wang, X., Zhao, Q., Lu, Q., 2019. Shifts of soil microbial community composition along a short-term invasion chronosequence of Spartina alterniflora in a Chinese estuary. Sci. Total Environ. 657, 222-233.

Zhang, G., Bai, J., Zhao, Q., Jia, J., Wang, W., Wang, X., 2020. Bacterial succession in salt marsh soils along a short-term invasion chronosequence of Spartina alterniflora in Yellow River estuary, China. Microb. Ecol. 79 (3), 644-661.

Zhao, Q., Bai, J., Gao, Y., Zhao, H., Zhang, G., Cui, B., 2020. Shifts of soil bacterial community along a salinity gradient in the Yellow River Delta. Land Degrad. Dev. 3116 , 2255-2267. 